\section{Autoantikörper gegen Titin}

W. Stöcker

Euroimmun Medizinische Labordiagnostika AG, Lübeck, Deutschland

Synonym(e) Titin-Antikörper

Englischer Begriff titin antibodies

Definition Autoantikörper gegen das Skelettmuskelstrukturprotein Titin.

Struktur Titin ist ein Protein der quer gestreiften Muskulatur mit einer Molmasse von etwa $3000 \mathrm{kDa}$, das größte Protein im Organismus. Es bildet in den Myofibrillen der Vertebraten ein Filamentsystem, das wichtig für die strukturelle Integrität und Elastizität der Muskulatur ist. Die immunogenen Regionen des Titins liegen auf einem Proteinfragment mit einer Molmasse von $30 \mathrm{kDa}$.

Funktion - Pathophysiologie Titin ist das erst im Jahr 1990 identifizierte Zielantigen der Myasthenia-gravis-assoziierten - Autoantikörper gegen quergestreifte Muskulatur.

Untersuchungsmaterial Serum, Plasma.

Probenstabilität Autoantikörper sind bei $+4{ }^{\circ} \mathrm{C}$ bis zu 2 Wochen lang beständig, bei $-20^{\circ} \mathrm{C}$ über Monate und Jahre hinweg.

Analytik Anti-Titin-Antikörper zeigen im indirekten Immunfluoreszenztest (IIFT, \ Immunfluoreszenz, indirekte) auf Skelettmuskulatur und Herz eine typische Querstreifung. Die
Ausgangsverdünnung ist 1:100. Klinisch signifikant sind Titer ab 1:1000. Für den monospezifischen Nachweis der Anti-TitinAntikörper stehen Linienblots ( $\triangleright$ Immunblot) zur Verfügung, sie verwenden als Antigensubstrat rekombinant hergestelltes MGT30-Peptid (die immunogenen Molekülabschnitte aus Titin).

\section{Referenzbereich - Erwachsene Negativ.}

Referenzbereich - Kinder Negativ.

Indikation Myasthenia gravis.

Interpretation Autoantikörper gegen Titin treten zusätzlich zu den $>$ Autoantikörper gegen Acetylcholinrezeptoren (ACHRAB) auf. Die Präsenz der Autoantikörper gegen Titin deutet tendenziell auf das Vorliegen eines Thymoms neben der Myasthenia gravis hin:

\begin{tabular}{l|l|l}
\hline & Prävalenz (\%) \\
\hline ACHRAB & MG & MG und Thymom \\
\hline Quergestreifte Muskeln & 85 & 100 \\
\hline Titin & 34 & 75 \\
\hline & 34 & 95
\end{tabular}

$A C H R A B$, Autoantikörper gegen Acetylcholinrezeptoren; $M G$, Myasthenia gravis

\section{Literatur}

Aarli JA, Stefansson K, Marton LS et al (1990) Patients with myasthenia gravis and thymoma have in their sera IgG autoantibodies against titin. Clin Exp Immunol 82:284-288

Romi F, Skeie GO, Aarli JA et al (2000) Muscle autoantibodies in subgroups of myasthenia gravis patients. J Neurol 247:369-375 